\title{
Drivers of Intention to Adopt Mobile Wallet: A Quantitative Study Among Females in Jakarta
}

\section{Elisya Laywilla, Jugindar Singh Kartar Singh, Benjamin Chan Yin Fah}

To Link this Article: http://dx.doi.org/10.6007/IJARBSS/v10-i11/8061～DOI:10.6007/IJARBSS/v10-i11/8061

Received: 07 September 2020, Revised: 09 October 2020, Accepted: 10 November 2020

Published Online: 29 November 2020

In-Text Citation: (Laywilla, Singh, \& Fah, 2020)

To Cite this Article: Laywilla, E., Singh, J. S. K., \& Fah, B. C. Y. (2020). Drivers of Intention to Adopt Mobile Wallet: A Quantitative Study Among Females in Jakarta. International Journal of Academic Research in Business and Social Sciences. 10(11), 804-820.

\section{Copyright: (c) 2020 The Author(s)}

Published by Human Resource Management Academic Research Society (www.hrmars.com)

This article is published under the Creative Commons Attribution (CC BY 4.0) license. Anyone may reproduce, distribute, translate and create derivative works of this article (for both commercial and non-commercial purposes), subject to full attribution to the original publication and authors. The full terms of this license may be seen at: http://creativecommons.org/licences/by/4.0/legalcode

Full Terms \& Conditions of access and use can be found at http://hrmars.com/index.php/pages/detail/publication-ethics 


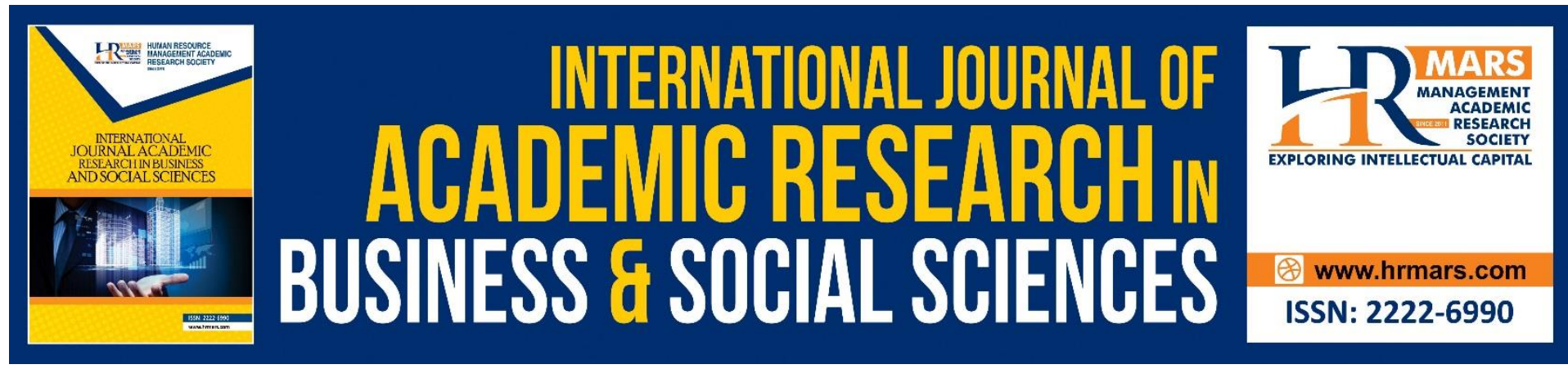

\title{
Drivers of Intention to Adopt Mobile Wallet: A Quantitative Study Among Females in Jakarta
}

\author{
Elisya Laywilla, Jugindar Singh Kartar Singh \\ Asia Pacific University of Technology and Innovation \\ Email: elisyalaywilla08@gmail.com, Jugindar.singh@apu.edu.my \\ Benjamin Chan Yin Fah \\ Universiti Tun Abdul Razak (UNIRAZAK) \\ Email: benjamin_chan@unirazak.edu.my
}

\begin{abstract}
The purpose of this research was to empirically analyse the determinants of the intention of females in Jakarta to use mobile wallets. More precisely, this paper examined the influence of performance expectancy, effort expectancy, social influence, and facilitating conditions on the intention to adopt mobile wallet. The target population were females' consumers in Jakarta. In this quantitative study, a survey method was used to collect primary data. By using a self-administered questionnaire, data were collected from 183 female respondents. Data were analysed using SPSS system, and the proposed model explained $55 \%$ of the variance in the dependant variable. The results revealed that all four predictors had a significant impact on the intention to adopt e-wallet. Effort expectance had the highest impact, and social influence had the lowest impact. From the results, marketeers and e-retailers can get a better understanding to develop strategies to improve the usage of mobile wallets in Jakarta. The adoption of mobile wallet in Indonesia is in an infancy stage, and this was one of the first studies that examined the predictors of the adoption of e-wallet among females in Jakarta.
\end{abstract}

Keywords: Mobile Wallet, Performance Expectancy, Effort Expectancy, Social Influence, Facilitating Conditions, Intention to Adopt, E-Wallet

\section{Introduction}

Indonesia is a big country with the fourth-largest population in the world of more than 270 million. Jakarta, as the capital city, has a total population of more than 10.5 million, which is approximately $4 \%$ of the nation's population. The population of females in Jakarta is 5.3 million, and it is slightly higher than males. Indonesia considered one of the leading markets among Southeast Asian countries besides Thailand and the Philippines (Suryanegara et al. 2018). The number of Internet users in Indonesia increased by $10 \%$ in 2018. It extends to 171 million people connected to the internet, which is $68.4 \%$ of the total population in Indonesia. A study indicates that the increment started since 2017, which recorded at $54.86 \%$ in 2017. There is no doubt that the digitalisation in Indonesia is kept significantly rising to $47 \%$ of the 
total population regularly using the internet and $80 \%$ of that number use the mobile devices for accessing information about products and services (Uy, 2019). E-commerce is also increasing, and the e-money transaction value in Indonesia in 2019 amounted to approximately 145 trillion Indonesian rupiahs. Comparatively, in 2011, only 981 billion Indonesian rupiahs were recorded (Statista, 2020). Bank transfers were the most popular method for e-commerce payments in Indonesia in 2019. Bank transfers accounted for almost 30 per cent of all e-commerce payments in 2019 (Statista, 2019). The value of e-commerce payments in Indonesia is expected to reach over 400 trillion rupiahs by 2023 . Based on the results of a survey done in 2020, about 84 per cent of e-payment users stated that they used e-payment transactions.

Mobile wallet refers to a software application that enables mobile devices to store payment cards, receipts, money balance, vouchers, tickets, loyalty cards, and other similar items. Users are allowed to store money and perform transactions through a phone or other device (Melissa et al., 2018). The usage of e-wallet is showing growth, and the initial transaction value for the mobile wallet in Indonesia was at approximately $\$ 1.5$ billion in 2018 (Timones, 2019). In 2020, the value is expected to exceed $\$ 15$ billion, which is aided through the massive success and rapid growth of mobile wallet adoption (Timones, 2019). It is reported that there is a total of thirty-one e-payment providers that are licensed under Bank Indonesia in 2018. Moreover, Indonesia and the Philippines have the most growth potential for an e-wallet. Indonesia has successfully increased its growth from 10\% to the total number of $36 \%$ in 2018 . There are approximately 150 players in Indonesia for e-wallet (Timones, 2019). The top ewallet players in Indonesia today are GOPAY, OVO, Dana, and LinkAja, and they have the highest number of active monthly users (MIA, 2020).

However, despite this significant growth of e-commerce and usage of e-wallets in Indonesia, cards are still the most dominant payment method in Indonesia with a total of $34 \%$ of the marketplace share, followed by bank transfers at $26 \%$. Digital wallet itself is in the third position with $20 \%$ that is almost half compared to the use of cards such as debit or credit card (J.P. Morgan, 2020). Based on data collected in a survey, only $26 \%$ of the 1,000 respondents said they chose to use e-wallets/e-money as a payment method when shopping online (MIA, 2020). The reasons might be due to the lack of facilitating conditions from the government as well as other restrictions and regulations for digital wallets. According to Bisara (2019), Indonesia is also considered as one of the countries with slow Internet speeds in Asia-Pacific with an average of $9.73 \mathrm{Mbps}$. It will become a challenge whereby the internet is the principal source for processing speedy transactions via mobile wallets.

Past studies have examined that determinants of mobile wallets. Past studies based on the technology acceptance model found a positive effect of usefulness and ease of use on consumers attitude (Shin, 2020). Based on the UTAUT model, past studies also found a positive relationship between the antecedents such as effort expectancy, and performance expectancy to the intention to use mobile wallets (Alkhunaizan and Love, 2012). Latha and Vatchala (2019) also found that performance expectancy was a significant predictor of the intention to use mobile payments. A study by Voronenko (2018) revealed that effort expectancy was a significant determinant of the intention to use a mobile wallet. A survey by Al-Saedi et al. (2020) that used the external factors of the UTAUT model found that performance expectancy was the most significant predictor of the intention to use mobile 
payment systems. However, some studies have shown different results that deviated from the UTAUT theory. A survey by Slade et al. (2015) showed that performance expectancy, social influence, innovativeness, and perceived risk significantly influenced intentions to adopt mobile payments. However, effort expectancy did not significantly affect mobile payments. Similarly, a study by Patel (2016) found that effort expectancy did not show a significant impact on intention to use mobile wallet services. The study by Al-Saedi et al. (2020) revealed that perceived risk did not have a significant effect on the intention to use M-payment systems. This points towards inconsistent results provided by past studies.

In addition to the inconsistent results shown in past studies, there is a dearth of studies that empirically tested the factors that influence the adoption of e-wallet among females in Jakarta. Specifically, the objectives of this study are as follows:

- To examine whether performance expectancy is related to the intention to adopt mobile wallet

- To examine whether effort expectancy is related to the intention to adopt mobile wallet

- To examine whether social influence is related to the intention to adopt mobile wallet

- To examine whether facilitating conditions are related to the intention to adopt mobile wallet

This is one of the first studies to empirically study the influence of the factors specified in the UTAUT theory on the intention to use mobile wallets by females in Indonesia. The results of this study will provide issuers of mobile wallets, e-marketeers, and retailers in the e-wallet business in Indonesia with a better understanding of the determinants of the intention to use mobile wallets by females in Indonesia.

\section{Literature Review Intention to Use}

There are several explanations on the concept of intention to use or behavioural intention. Schwartz (2019) referred to that behaviour as an intention to action that encompasses several parameters to describe what is a person is doing, how behaviour is performed or what was achieved. He argued that these parameters are pre-empirical concepts and the 'want' parameter only indicates that intentional action is motivated. The technology acceptance model and theory of planned behaviour can be referred to provide further explanation on intention or behavioural intention (Ajzen, 1991; Davis et al., 1989). As posited in the theory of planned behaviour, a person's intention to use systems or devices such as usage of mobile wallets, in this case, is influenced by the person attitude to act. The persons' expectations further depend on subjective norms and perceived behavioural control. As explained by Ajzen (1991), a person's intention can further influence actual behaviour. Past studies have revealed that the constructs specified in the theory of planned behaviour are positive predictors of behavioural intention (e.g., Choi and Johnson, 2019; Maichum, Parichatnon, and Peng (2016). The study by Choi and Johnson (2019) revealed that the three constructs contributed around $50.8 \%$ of the variance in intention to purchase. In addition, the technology acceptance model (TAM) is one of the most prominent models that can be referred to explain the acceptance of technology (Lee et al., 2003). According to TAM, an individual's intention to adopt or use technology or systems is influenced by his or her behavioural intention. Subsequently, the 
intention to use further influences an individual's attitude towards the technology and the perceived usefulness of the technology (Davis et al., 1989).

\section{Performance Expectancy and Intention to Use the Mobile Wallet}

Performance expectancy (PE) is one of the components in Unified Theory of Acceptance and Use of Technology (UTAUT) which develop by Venkatesh, Morris, and Davis (2003). Perceived expectancy is closely related to perceived usefulness that was specified by Davies et al. (1989). Initially, the focus of the UTAUT theory was on the adoption or usage of technology. Subsequently, researchers extended the use of the UTAUT theory to study the adoption and acceptance of web-based applications (e.g., Decman, 2015; Ahmad and Love, 2013). However, studies have now shown that the UTAUT model can be used to study the intention to use mobile devices and systems (e.g., Thakur, 203); Al-Saedi et al., 2020). Performance expectancy is included in the UTAUT model to predict the acceptance by user and continuing usage of a system or technology. According to Venkatesh et al. (2003), performance expectancy refers to the extent whereby an individual perceives that the system is useful, and the system will assist or facilitate the task or job performance.

Several researchers consider performance expectancy as a significant influencer of the adoption and subsequent usage of information systems and mobile devices (e.g., Thakur, 2013). The study by Al-Saedi et al. (2020) focussed on the external factors of the UTAUT model and found that performance expectancy was the most significant predictor of the intention to use mobile payment systems. The results of a study by Thakur (2013) revealed that performance expectancy had a significant influence on the intention to use systems or devices. Studies have also found that performance expectance is one of the determinants of intention to use mobile payments (e.g., Yeh and Tseng, 2017; Thakur, 2013). The study by Yeh and Tseng (2017) studied the behaviour intention of students to use mobile payments. The study revealed that effort expectancy was a positive and significant predictor of intention to use mobile payments. Similarly, the research the Thakur (2013) further confirmed that performance expectancy was $s$ positive predictor of intention to adopt mobile payment services. Slade et al. (2015) further added that performance expectancy was one of the most significant predictors of intention to use mobile payments. However, a study by Jaradat and Rababaa (2013) found that performance expectancy was only that third most potent predictor of intention to use M-commerce services in Jordan. Past studies have also found support for the role of performance expectancy in predicting intention to use e-wallets (e.g., Madan ad Yadav, 2016). The survey by Madan and Yadav (2016) found a positive relationship between effort expectancy and intention to use a mobile wallet. In addition, effort expectancy had the most substantial effect on the intention to use a mobile wallet. Support on the positive relationship between performance expectancy and intention to use mobile wallet has been found in other studies (Wang and Yi, 2012; Yan and Yang, 2015). The results of a study by Isa et al. (2017) deviated from the UTAUT model and revealed that performance expectancy was not a significant predictor of consumer intention to use mobile payments. It can be concluded that performance expectancy is one of the key predictors of intention to use mobile wallet services. Based on the literature review, it is posited in this study that: $\mathrm{H}_{1}$ : Performance Expectancy is related to the intention to adopt mobile wallet by females in Jakarta. 


\section{Effort Expectancy and Intention to Adopt Mobile Wallet}

Effort expectancy is one of the constructs specified in the UTAUT model. As explained by Venkatesh et al. (2012), effort expectancy refers to scale or degree of ease perceived by a person that is associated with his or her usage of systems or technology. This construct is also similar to the construct stated in the technology acceptance model, namely the perceived ease of use. In the technology acceptance model, perceived ease of use refers to the perceived level at which the adoption or usage of a technology or system will be free of effort (Davis, 1989). Past researchers have studied effort expectance as one of the determinants of the intention to adopt or use systems and technology (Wang and Yi, 2012; Pham and Ho, 2014; Yan and Yang, 2015).

Past studies have revealed that there is a relationship between effort expectancy and use of systems or technology (Alraja, et al., 2016; Madan and Yadav 2016). However, the outcomes of past studies have shown inconsistent or contradictory results. A study by Abrahão, et al. (2016) revealed that effort expectancy was a positive and significant predictor of intention to use systems. Similarly, another study by Oliveira et al. (2016) also showed that effort expectancy was significantly related to the adoption of mobile payment. Further support on the positive relationship that was revealed in a study by Trivedi (2016). This study showed that effort expectancy was a critical determinant, especially among millennials who prefer easier completion of task without much complexity.

On the contrary, a survey by Slade et al. (2015) revealed that constructs such as performance expectancy, social influence and perceived risk were significantly related to intention to adopt mobile payments, but effort expectancy did not significantly affect mobile payments. Similarly, a study by Patel (2016) found that effort expectancy did not show a significant impact on intention to use mobile wallet services. Further support was found a study by Madan and Yadav (2016). This study found that constructs such as performance expectancy, social influence, and facilitating conditions were significantly related to intention to use a mobile wallet, but effort expectancy was not significantly related to intention to use a mobile wallet. Therefore, it can be concluded that past studies show contradictory results. In this study, it is hypothesised that:

$\mathrm{H}$ 2: Effort Expectancy is related to the intention to adopt mobile wallet by females in Jakarta.

\section{Social Influence and Intention to Adopt Mobile wallet}

Social Influence is another construct that is defined in the UTAUT model by Venkatesh et al. (2003). As explained by Venkatesh et al. (2012), social influence refers to the extent to which consumers perceive that others, such as family and friends, believe that they should use a system or technology. Riquelme and Rios (2010) further explained that social influence is the degree to which family, friends and peers influence the opinion of consumers about the use of a product or service, and this includes systems. In simpler terms, it refers to the influence of family and friends regarding the use of systems and technology by an individual. Friedman (2006) argued that social influence links the occupants of different social positions. Interpersonal influence affects people's opinions and attitudes, and the influence process can result in agreements. Therefore, social influence is typically associated with a consumer's attitudes, behaviours and opinions that are influenced by interactions of certain other individuals. Social influence is closely related to subjective norms. Based on network theory, social norms can be interpreted as an influence that is originating from the predominance of 
one person's behaviour on another person's network that adheres the network's characteristics (Lorenz \& Buhtz, 2017).

Past researchers have studied the factors that influence intentions to adopt or use systems and technologies (e.g., Madan and Yadav, 2016; Leng and Lada, 2011). The result of a study by Prabhakaran, Vasantha and Sarika (2020) showed that social influence had a high impact on the intention to use mobile wallets. A survey by Leng and Lada (2011) revealed that social influences had a moderate effect on consumers intention to adopt mobile payments. Khatimah et al. (2019) also found that behavioural intention of e-money by consumers was positively influenced by social influence. A study by Alshare et al. (2011) studied the role of culture and found that social influence is a positive and significant predictor of users' intention to use mobile devices in societies that practice collectivism cultural values. Contradictory results were also found in some studies (e.g., Kwateng, Atiemo and Appiah, 2019; Arine, Zain and Rashid, 2020; Isa et al., 2017). This may be because millennials are technology savvy and willing to try new things and take the risk of using new technology. Another study by Kwateng, Atiemo and Appiah (2019) also found that social influence did not significantly impact consumers intention to adopt systems or technologies. Therefore, this construct specified in the UTAUT model also shows contradictory results from past studies. In this study, it is hypothesised that:

$\mathrm{H} 3$ : Social influence is related to the intention to adopt mobile wallet by females in Jakarta.

\section{Facilitating Conditions and Intention to Adopt Mobile Wallet}

Triandis (1980) referred to facilitating conditions as the components that make a task or an activity to become easier to perform for an individual. Facilitating conditions is another construct in the UTAUT model. It is defined as the belief by an individual on the degree of existence of technical and organisational infrastructure that will substantiate or corroborate the use of a system or technology (Venkatesh et al., 2003). Venkatesh et al. (2003) further added that facilitating conditions encompass available of help, support, and guidance for users on overcoming any problems or difficulties they may encounter when using a system or device. Therefore, in this study, facilitating conditions refers to an environment where any obstacles are removed and help, or assistance is readily available. It is the belief by a user concerning the availability of access to resources that are necessary and required to facilitate the completion of a function or service (Cheong et al., 2004). As stressed by Yang and Forney (2013), one of the crucial preconditions to encourage usage of mobile devices are the facilitating conditions. This encompasses the mobile devices capabilities and lower cost of procuring the services.

be influenced by mobile device capabilities and low fees for receiving services or for purchasing a mobile device

Past researchers have examined the impact of facilitating conditions on the intention to use systems or technology (e.g., Abidin et al., 2017; Teo, 2009). The study by Abdidin et al. (2017) found a positive and significant relationship between facilitating conditions and intention to use or adopt systems or technology. Another related study on the intention to use the electronic payment system revealed that facilitating conditions had a positive impact on the customer acceptance of the electronic payment system (Isa, et al., 2017). Another study by Teo (2009) found a positive relationship between facilitating conditions and usage of technology, but the attitude towards usage mediated the relationship. On the contrary, some 
studies have found that facilitating conditions were not a predictor of intention to use systems including mobile wallet (e.g., Arine, Zain and Rashid, 2020; Alkhunaizan, and Love, 2012). The study by Arine Zain and Rashid (2020) found that facilitating conditions did not affect the intention to use e-wallets in Brunei. Similarly, the survey by Alkhunaizan, and Love (2012) also found that facilitating conditions did not show significant influence on the usage of mobile commerce. The past literature pointed towards inconsistency in findings of the role of facilitating conditions. In this study, it is hypothesised that:

$\mathrm{H} 4$ : Facilitating conditions are related to the intention to adopt mobile wallet by females in Jakarta.

\section{Methodology and Research Design}

Introduction and Research Design

This study was based on a positivism philosophy whereby the theory and objective knowledge was available. A deductive approach was suitable, and hypotheses were developed to study the causal relationship between the variables. This was a quantitative study, and primary data was collected in numerical format. In this cross-sectional research, a self-administered questionnaire was used to collect data from the target population. The self-administered questionnaires were distributed electronically using the internet or delivered by hand and collected later (Saunders et al., 2016). Non-probability sampling was used to collect data, and SSPS software was used for data analysis.

Populations, Sampling, and Sample Size

Saunders et al. (2016), argued that it would be impracticable to collect data from the entire population and sampling is required. The target population in this research covered the female consumers in Jakarta who have knowledge of mobile wallet. The target population were around a total of 2,922,708 females (Badan Pusat Statistik (BPS) - Statistics of DKI Jakarta Province, 2020). The participants were required to meet the inclusion criteria, which included their gender and knowledge of mobile wallets. In this study, a proper sampling frame was not available, and as such, snowball and convenience sampling techniques were appropriate (Saunders et al., 2016). As stated by Saunders et al. (2016), non-probability sampling techniques were more practical in this study. The sample size was based on the formula that was developed by Tabachnick and Fidell (2001). According to the formula, the sample size must be at least " $50+8$ " whereby " $\mathrm{m}$ " is the number of predictors. Based on the formula, the minimum sample is 82 respondents. However, for better accuracy for the results, the targeted sample size was set at 100 respondents.

Instrumentation and Questionnaire Design

A self-administered questionnaire is chosen because of its convenience, lower cost, and more anonymity (Saunders et al., 2016). The questionnaire was divided into two sections. The first section covered data on the personal information of respondents such as education and income. The next section was all attitude-based questions based on five-point Likert scales. The questions were adapted from past studies. The measurement for each factor had been analysed differently by different scholars. Performance expectancy was measured with four (4) measurement questions, effort expectancy was based on five (5) measurement questions, and facilitating conditions was based on six (6) measurement questions adapted from studies by Cheng, et al., 2018 and Megadewandanu, 2016). For social influence, the five measurement questions were adapted from studies by Venkatesh \& Davis, 2000; and Cheng 
et al., 2018). Questions for intention to use were adapted from studies by Venkatesh \& Davis, 2000); Bhattacherjee, 200; Cheng et al., 2018); Megadewandanu, 2016). The conceptual framework is shown in Figure 1. respondents.

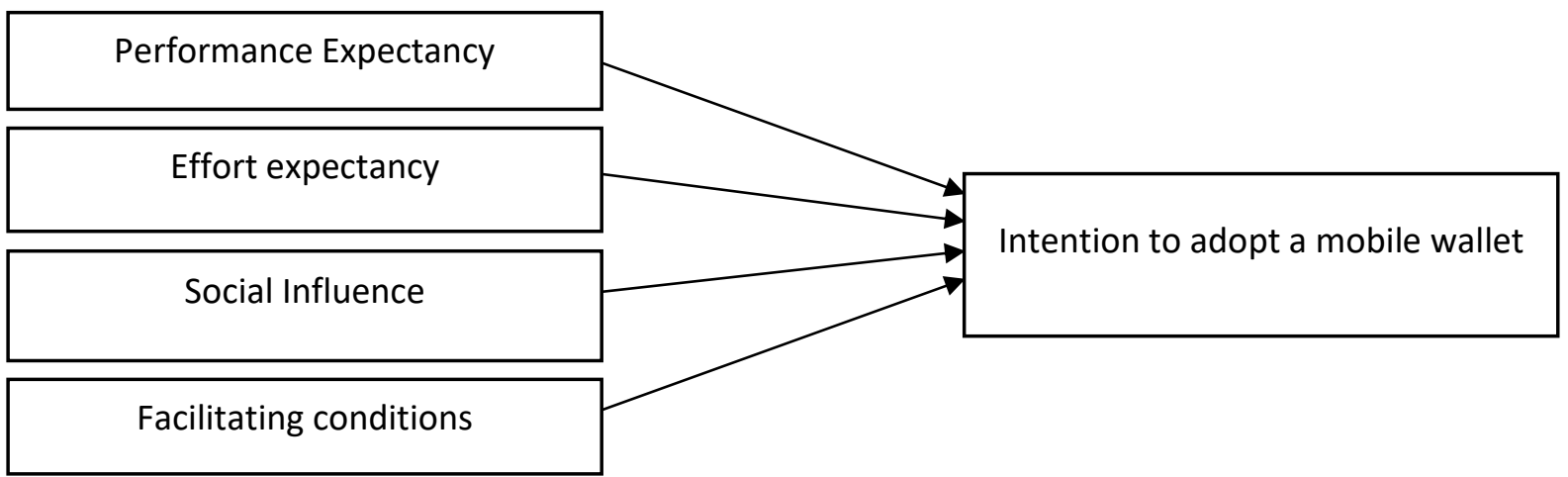

Figure 1: The conceptual framework. Source: Developed by the research based on UTAUT Model by Venkatesh et al. (2003).

Data Collection and preliminary checking In this study, an online survey is a preferred method since the sampling elements were people who were technology savvy. A survey method was utilised, and a hybrid method was used to improve the response rate. The questionnaires were distributed electronically and directly by hand. Since the response rate from electronic mail was not good, reminders were sent. A total of 187 responses were received, and five questionnaires were removed due to omissions and errors. In this study, ethical considerations that covered privacy, confidentiality and absence of deception was strictly observed. Finally, there were 183 useful questionnaires.

\section{Data analysis and hypothesis testing}

The first step was to edit the data and get the feel of the data using descriptive statistics. The data was coded and entered in Excel spreadsheet. After that, it was uploaded to the SPSS system to generate descriptive and inferential statistics. Frequency distributions were checked to get a feel of the data. The goodness of data was based on reliability testing and normality testing. Hypothesis testing is based on multiple regression analysis. Descriptive statistics were also generated to describe the characteristics of the respondents (Sekaran, 2003).

\section{Results}

Demographic Profiles of the Respondents

Based on the age profile, most of the respondent were between $20-34$ years old $(92.3 \%)$. Based on occupation, most of the respondents were students (53.4\%), followed by employees' inn organisations (36.2\%). The rest were self-employed and entrepreneurs. In terms of income level, most of the respondents were in the income level of less than Indonesian Rupiah (Rp) 1,000,000 (35\%). Another 27\% earned between Rp 1,000,000 $2,500,000$ and $22 \%$ earned between $\mathrm{Rp} 2,500,001-5,000,000$. The rest earned more than $\mathrm{Rp} 5,000,000$. Regarding the experience of using a mobile wallet, most of the respondents were using mobile wallet between 2 to 5 years (53.6\%). Another $42 \%$ used a mobile wallet for less than two years. 
Reliability test to measure consistency

Reliability of the data was tested based on the Cronbach Alpha value that was generated using SPSS. The closer the value to 1 means that the data achieves consistency and is reliable (Taherdoost, 2016). Reliability is required to confirm the degree in which a measurement of a phenomenon serves a stable and consistent result (Carmines and Zeller,1979). As a rule of thumb, the minimum of Cronbach's Alpha coefficient must be at least 0.70 or higher to ensure the data to be reliable (Whitley, 2002). The values of 0.8 indicate more excellent reliability. However, Cronbach Alpha values of $0.6-0.7$ are also considered as an acceptable level of reliability (Zikmund et al., 2013). In this study, all the Cronbach Alpha Value are above 0.7. Therefore, the reliability of the data is confirmed.

Table 1: Reliability Testing

\begin{tabular}{lll}
\hline Variables of The Study & Cronbach's Alpha (r) & N of Items \\
\hline Performance Expectancy & 0.835 & 4 \\
Effort Expectancy & 0.817 & 5 \\
Social Influence & 0.715 & 5 \\
Facilitating conditions & 0.795 & 6 \\
Intention to Adopt Mobile Wallet & 0.898 & 6 \\
\hline
\end{tabular}

Normality Test

The normality test is essential to determine the normal distribution of the data. The skewness and kurtosis are used to understand the distribution of the data. According to (Muzaffar, 2016), the acceptable range of skewness and kurtosis is -2 to +2 . The data from the study shows that the skewness value for all variables was in between (-.070) to (-.703), which indicates a normal distribution and considered as acceptable. In addition, the value of the kurtosis for all variables also ranges between $(0.22)$ to $(-.454)$, which also means data is normally distributed.

Table 2: Normality Test

\begin{tabular}{lll}
\hline Variables & Skewness & Kurtosis \\
\hline Performance Expectancy & -.703 & -.132 \\
Effort Expectancy & -.411 & -.454 \\
Social Influence & -.070 & -.239 \\
Facilitating Conditions & -.098 & -.440 \\
Behavioral Intention & -.563 & .022 \\
\hline
\end{tabular}

Pearson Correlation Analysis

Pearson Correlations was utilised to measure the strength and direction of association that exists between two variables measured on an interval scale. According to Sekaran (2003), the correlation value ranged from -1.0 to +1.0 , and a value of -1 or +1 denotes a perfect negative relationship and perfect positive relationship. Meanwhile, 0.00 means that there is no relationship between independent variables and the dependent variable (Obilor and Amadi, 2018). All the independent variables in this study have a positive and significant relationship. The results show that facilitating conditions and effort expectancy has the strongest correlation towards the intention to adopt mobile wallets by females in Jakarta. 
Table 3: Pearson Correlation Coefficient

\begin{tabular}{llllllll}
\hline No & Variables & $\mathbf{1}$ & $\mathbf{2}$ & $\mathbf{3}$ & $\mathbf{4}$ & $\mathbf{5}$ \\
\hline 1 & Performance Expectancy & 1 & & & & & \\
2 & Effort Expectancy & 0.553 & 1 & & & \\
3 & Social Influence & 0.326 & 0.337 & 1 & & \\
4 & Facilitating Conditions & 0.491 & 0.584 & 0.470 & 1 & \\
5 & Behavioural Intention & 0.555 & 0.616 & 0.495 & 0.625 & 1 \\
\hline
\end{tabular}

Multiple Regression Test and Model Fit Summary

Multiple regression analysis is a regression that analyses more than one independent variable with one dependent variable. The value of $\mathrm{R}$ Square refers to the coefficient of determination, whereby it measures the strength of the predictors, which range between 0 and 1 . The Adjusted R Square further gives an idea of how well the model will be generalised (Reisinger, 1997). According to Reisinger (1997), a great $R$ square must at least have a $p$-value of 0.3 in order in order to be accepted to has a cause-effect relationship. This study shows an r-square value of 0.543 which means there is a moderately strong effect from all the independent variables to the dependent variable. It indicates that the four independent variables, namely Performance Expectancy, Effort Expectancy, Social Influence (SI), and Facilitating Conditions (FC) explained $54.3 \%$ variance in the intention to adopt mobile wallet.

Table 4: Model Fit Summary

\begin{tabular}{lc}
\hline Multiple R & 0.744 \\
\hline Coefficient of Determination (R Square) & 0.553 \\
F Value & 55.093 \\
Adjusted R Square & 0.543 \\
Sig & .000 \\
\hline
\end{tabular}

The standardised coefficient is based on the Beta (B) value. In this study, all Beta values are positive. This test was done to find out whether the hypothesis will be accepted or rejected by examining the significance value ( $p$-value). A hypothesis is accepted when the significance value is below $5 \%(>0.05)$. An alternate hypothesis is rejected when the significance value is more than 0.05 . This analysis also looked at the correlation between one continuous dependent variable with four continuous independent variables. In this study, all the independent variables (IVs) were positively related to the dependent variable. All four predictors also have a significant relationship with the dependent variable with a significant level below $0.05(p<0.05)$. Effort Expectancy $(E E)$ had the strongest impact with a Beta (B) value of 0.280 . Therefore, all four hypotheses were proven and accepted. 
Table 5: Coefficients

\begin{tabular}{ll}
$\begin{array}{l}\text { Unstandardised } \\
\text { Coefficients }\end{array}$ & $\begin{array}{l}\text { Standardised } \\
\text { Coefficients }\end{array}$ \\
\hline
\end{tabular}

\begin{tabular}{llllll} 
Model & B & Std. Error & Beta & t & Sig. \\
\hline (Constant) & -1.997 & 1.554 & & -1.285 & .200 \\
Performance Expectancy & .350 & .108 & .202 & 3.245 & .001 \\
Effort Expectancy & .418 & .100 & .280 & 4.195 & .000 \\
Social Influence & .250 & .068 & .211 & 3.692 & .000 \\
Facilitating Conditions & .331 & .085 & .263 & 3.891 & .000 \\
\hline
\end{tabular}

\section{Discussion, Implications and Recommendations}

The first hypothesis was to prove that there is a significant relationship between performance expectancy and intention to adopt a mobile wallet. The result showed that performance expectancy had a positive and significant impact and intention to adopt a mobile wallet. This result is aligned with previous research by Yeh and Tseng (2017), Slade, et al. (2015), and Madan and Yadav (2016). Therefore, the results show that the females in Jakarta perceive that using mobile wallet will help them to carry out purchases. The consumers will find the usage of mobile wallet services to be a convenient and faster mode of payment if the performance expectancy is good. The higher the performance expectancy, the higher will be their intention to use the e-wallet. Hence, it is crucial to provide a mobile wallet service with a high-performance expectancy that works well effectively and seamlessly. In this study, performance expectancy had the lowest impact compared to other constructs. This may be due to the maturity level of technologies that make it easier to use e-wallets.

The second hypothesis was to find out the association between effort expectancy and intention to adopt mobile wallets. The results of this study also indicate a positive and significant relationship with intention to adopt e-wallet. Past studies have found inconsistent findings on the impact of effort expectancy on the intention to adopt mobile wallet and other systems. This study supports the UTAUT model and the findings by Venkatesh et al. (2003). The results are also consistent with past studies by Alraja et al. (2016), Madan and Yadav (2016) and Abrahao, et al. (2016). Therefore, the higher the degree of ease perceived by females in Jakarta, the higher will be the usage of e-wallet by females in Jakarta. In other words, if females in Jakarta perceive that usage of e-wallet will be free of effort, the higher will be the usage of e-wallet. In this study, effort expectancy had the most substantial impact on the intention to use mobile wallets, and an increment in effort expectancy will definitely give a positive effect on the growth if mobile wallet services.

The third hypothesis was to examine the influence of social influence on the intention to adopt mobile wallets. The results of this study showed a positive and significant effect on the intention to use mobile wallets. The results conform to the UTAUT model by Venkatesh et al. (2003). The results are also consistent with past studies by Leng and Lada (2011) and Alshare et al. (2014) that also fund a positive and significant relationship. Therefore, this study shows that when female consumers are influenced by family and friends to adopt mobile wallets. The higher the social influence by family and friends, the higher will be the intention to use mobile wallets. 
The fourth hypothesis was to examine the relationship between facilitating conditions and intention to adopt mobile wallet among females in Jakarta. The results revealed a positive and significant impact on intention to adopt e-wallets. The result conforms to the UTAUT model and is consistent with results from past studies by lsa et al., (2017); Abidin et al. (2017) and Teo, (2009) that also found a positive and significant relationship. In this study, facilitating conditions also had the second most substantial relationship with the intention to use mobile wallets. Therefore, to increase the adoption of mobile wallets by females in Jakarta, the existence of technical and organisational infrastructure that will substantiate or corroborate the use of a system or technology is essential. The higher the belief by a user concerning the availability of access to resources that are necessary and required to facilitate the completion of a function or service, the higher will the success of the adoption of mobile wallets.

From the practical perspective, the results of this study inform various organizations and policy makers on the strategies to increase the adoption of mobile wallets. This study provides a foundation for the further development and advancement of the acceptance and use of mobile wallets. In this study, all the four independent constructs had a positive and significant impact on intention to adopt mobile wallet in Jakarta by female customers. The results suggest that investments in the enhancement and development of performance expectancy, effort expectancy, social influence and facilitating conditions are necessary in order to promote the adoption of mobile wallets by females. Effort expectancy followed by facilitating conditions had the most substantial impact. Therefore, marketers and the authorities driving the growth of mobile wallets should invest in ensuring the usage of the mobile wallet is free of effort. Facilitating conditions was the next strongest predictor and organisations involved in developing the mobile wallet should invest in technical and organisational infrastructure that will substantiate or corroborate the use of mobile wallets. Better and faster availability of access to resources that are necessary and required to facilitate the completion of a function or service the higher will contribute towards the success of the adoption of mobile wallets. A good performance from mobile wallet services with low effort will enhance the loyalty of users and increase the interest of more new users. An excellent and straightforward user interface is required for users to understand more quickly and be attracted by visual ability. From a theoretical and academic perspective, the results of this study will add to the current body of knowledge and may be useful to other researchers.

The results of this study made a sizeable theoretical, and contextual contribution to the current overall body by addressing the gap that was identified in current literature. This research addressed the gap or deficiency in literature related to this study. It was identified in this study that there is a paucity of research that validate the model of UTAUT to explain the determinants that influence female consumers in Jakarta intention to use mobile wallets. Therefore, this study added to the current body of knowledge by examining the model of UTAUT to explain female consumers intention to use mobile wallets. The results of this study confirmed the validity of UTAUT by proving that the constructors stated in the UTAUT theory are predictors of intention to adopt devices such as mobile wallet in this study. Despite the inconsistent results found in past studies, this study revealed that effort expectancy is the strongest predictor of intention to adopt mobile wallet by females in Jakarta. Since this study has confirmed the viability of UTAUT in researching intention and use systems or devices, the model can be replicated in different countries and respondents when researching on the 
intention to use mobile wallets. Academicians and future researchers can build on the results of this study and continue further research.

There are some limitations associated in this study that can pave the way for future studies. Although the sample size was adequate to generate good results, a larger sample size would have provided more robust results. Future studies should consider larger samples. Secondly, the respondents for this study were drawn from females residing in Jakarta. This can limit the generalizability of the results. Future research should consider respondents from other towns. This study did not consider the differences in the intention to adopt mobile wallets based on categorical variables such as age. Age differences may affect the strength and direction of the relationship between the variables. Therefore, future studies should consider moderators, such as age. The study also did not consider the differences between urban and rural areas. Future research can investigate the differences between respondents from urban areas and respondents from rural areas.

\section{References}

Abidin, W. Z., Rivera, O., Maarop, N., \& Hassan, N. H. (2017, July). Mobile payment framework for the unbanked Filipinos. In 2017 International Conference on Research and Innovation in Information Systems (ICRIIS), 1-6). doi:10.1109/icriis.2017.8002478

Abrahão, R. D. S., Moriguchi, S., \& Andrade, D. (2016). Intention of adoption of mobile payment: An analysis in the light of the Unified Theory of Acceptance and Use of Technology (UTAUT). RAI Revista de Administração e Inovação, 13(3), 221-230.

Ahmad, A. and Love, S. (2013). Factors influencing students' acceptance of mlearning: an investigation in higher education. The International Review of Research in Open and Distance Learning, 14(5), 82-107.

Ajzen, I. (1991). The Theory of Planned Behavior. Organisational Behavior and Human Decision Processes, December, 50(2), 179-211.

Alkhunaizan, A., \& Love, S. (2012). What drives mobile commerce? An empirical evaluation of the revised UTAUT model. International Journal of Management and Marketing Academy, 2(1), 82-99.

Alshare, K., Mesak, H., Grandon, E., and Badri, M. (2011). Examining the moderating role of national culture on an extended technology acceptance model. Journal of Global Information Technology Management, 14(3), 27-53.

Alraja, M. N., Hammami, S., Chikhi, B. \& Fekir, S. (2016). The Influence of Effort and Performance Expectancy on Employees to Adopt E-government: Evidence from Oman. International Review of Management and Marketing, 6(4), 930-934.

Al-Saedi, K., Al-Emran, M., Ramayah, T., \& Abusham, E. (2020). Developing a general extended UTAUT model for M-payment adoption. Technology in Society, 62, 101293. doi: https://doi.org/10.1016/j.techsoc.2020.101293

Arine, M. A., Zain, H. A., \& Rashid, N. H. (2020). Advancing Towards a Cashless Society: The acceptance of eWallet in Brunei Darussalam. In Financial Technology and Disruptive Innovation in ASEAN (pp. 203-215). IGI Global.

Badan Pusat Statistik (BPS) - Statistics of DKI Jakarta Province. (2020). Statistics Indonesia DKI Jakarta Province. Jakarta: Statistics Indonesia. Retrieved from https://jakarta.bps.go.id/

Bhattacherjee, A. (2001). Understanding Information Systems Continuance: An ExpectationConfirmation Model. MIS Quarterly, September, 25(3), 351-370. 
Bisara, D. (2019). Indonesia's E-commerce Market Larger Than Estimated, Consumer Habits Changing: Study. Retrieved from https://jakartaglobe.id/business/indonesiasecommerce-market-larger-than-

Cheong, J. H., Park, M. C., and Hwang, J. H. (2004). Mobile payment adoption in Korea: switching from credit card. ITS 15th Biennial Conference, (pp 4-7) Berlin

Choi, D., \& Johnson, K. K. (2019). Influences of environmental and hedonic motivations on intention to purchase green products: An extension of the theory of planned behavior. Sustainable Production and Consumption, 18, 145-155.

Davis, F. D., Bagozzi, R. P., and Warshaw, P. R. (1989). User acceptance of computer technology: a comparison of two theoretical models. Management Science, 35(8), 982-1003.

Davis, F. D. (1989). Perceived usefulness, perceived ease of use and user acceptance of information technology. MIS Quarterly, 13(3), 319-339.

Decman, M. (2015). Modeling the acceptance of e-learning in mandatory environments of higher education: the influence of previous education and gender. Computers in Human Behavior, 49(2015), 272-281.

Friedkin, N. E. (2006). A structural theory of social influence (Vol. 13). Cambridge University Press.

Isa, M. A. M., Nasrul, F., Senan, R., \& Mohamed, S. (2017). The consumer acceptance towards electronic payment system. In Global Conference on Business and Economics Research (GCBER) (pp. 14-15). Universiti Putra Malaysia, Malaysia

Jaradat, M. I. R. M., \& Rababaa, M. S. A. (2013). Assessing Key Factor that Influence on the Acceptance of Mobile Commerce Based on Modified UTAUT. International Journal of Business and Management, 8(23), 102-112.

Morgan, J. P. (2020). E-commerce Payments Trends: Indonesia. Retrieved from https://www.jpmorgan.com/merchant-services/insights/reports/indonesia

Khatimah, H., Susanto, P., \& Abdullah, N. L. (2019). Hedonic Motivation and Social Influence on Behavioral Intention of E-Money: The Role of Payment Habit as A Mediator. International Journal of Entrepreneurship, 23(1), 1-9.

Kwateng, K. O., Atiemo, K. A. O., \& Appiah, C. (2019). Acceptance and use of mobile banking: an application of UTAUT2. Journal of enterprise information management, 32(1), 118-151.

Latha, R., \& Vatchala, C. (2019). Exploring the Factors Influencing the Mobile Wallet Usage Intention. International Journal of Engineering Development and Research, 7(2), 7781.

Lee, Y., Kozar, K. A., and Larsen, K. R. T. (2003). The technology acceptance model: past, present, and future. Communications of the AIS, 12(1), 752-80

Leng, G., \& Lada, S. (2011). An Exploration of Social Networking Sites (SNS) Adoption in Malaysia Using Technology Acceptance Model (TAM), Theory of Planned Behaviour (TPB) And Intrinsic Motivation. Journal of Internet Banking \& Commerce, 16(2), 1-27.

Lorenz, G. V., \& Buhtz, K. (2017). Social Influence in Technology Adoption Research: A Literature Review and Research Agenda. Guimarães, Association for Information Systems AIS Electronic Library (AISeL).

Madan, K., \& Yadav, R. (2016). Behavioural Intention to Adopt Mobile Wallet: A Developing Country Perspective. Journal of Indian Business Research, 8(3), 227-244.

Maichum, K., Parichatnon, S., \& Peng, K. C. (2016). Application of the extended theory of 
planned behaviour model to investigate purchase intention of green products among Thai consumers. Sustainability, 8(10), 1077.

Megadewandanu, S. S., \&. P. (2016). Exploring Mobile Wallet Adoption in Indonesia Using UTAUT2: An Approach from Consumer Perspective. Yogyakarta, IEEE.

Cheng, F. M., Khim, C., and Thai, S. (2018). Consumer Adoption of E-Wallets: A Study of Millennials at the Institute of Foreign Languages, Cambodia, Proceedings of the 21st Asia-Pacific Conference on Global Business, Economics, Finance \& Social Sciences (AP18Taiwan Conference), Taipei Taiwan, 2018, paper ID: W812

MIA. (2020). Top E-Wallet in Indonesia Q2 2019-2020. Retrieved from https://marketinginasia.com/2020/08/19/top-e-wallet-in-indonesia-q2-2019-2020/

Oliveira, T., Thomas, M., Baptista, G., \& Campos, F. (2016). Mobile payment: Understanding the determinants of customer adoption and intention to recommend the technology. Computers in Human Behaviour, August, Volume 61, 404-414.

Patel, V. (2016). Young Consumer's Intention to Use Mobile Wallet Services: Empirical Investigation using UTAUT Model. In Nirmal International Conference (NICOM), Retrieved from https://www. researchgate. net/publication/303685121.

Pham, T. T. T., and Ho, J. C. (2014). What are the core drivers in consumer adoption of NFCbased mobile payments? A proposed research framework, Management of Engineering \&Technology (PICMET), 2014 Portland International Conference, Kanazawa, (3041-3049). Portland.

Prabhakaran, S., Vasantha, D. S., \& Sarika, P. (2020). Effect of social influence on intention to use mobile wallet with the mediating effect of promotional benefits. Journal of Xi'an University of Architecture \& Technology, 12, 3003-3019.

Riquelme, H. E., and Rios, R. E. (2010). The moderating effect of gender on the adoption of mobile banking. International Journal of Bank Marketing, 28(5), 328-341.

Saunders, M., Lewis, P., \& Thornhill, A. (2016). Research methods for business students. 5th ed. Harlow: Pearson education.

Schwartz, W. (2019). Descriptive Psychology and the Person Concept: Essential Attributes of Persons and Behavior. Academic Press.

Sekaran, U. (2003). Research Methods for Business: A Skill-building Approach. New York: Wiley \& Sons

Shin, D. H. (2009). Towards an understanding of the consumer acceptance of mobile wallet. Computers in Human Behavior, 25(6), 1343-1354.

Slade, E. L., Dwivedi, Y. K., Piercy, N. C., \& Williams, M. D. (2015). Modelling consumers' adoption intentions of remote mobile payments in the United Kingdom: extending UTAUT with innovativeness, risk, and trust. Psychology \& Marketing, 32(8), 860-873.

Statista. (2020). Most used e-wallet for the first time among respondents in Indonesia in 2020. Retrieved from : https://www.statista.com/statistics/1103861/indonesiamost-used-e-wallet-by-first-timers/

Suryanegara, M., \& Arifin, A. S., Asvial, M., Ramli, K., Nashiruddin, M. I., \& Hayati, N. (2018). What are the Indonesian Concerns about the Internet of Things (IOT)? Portraying the Profile of the Prospective Market. IEEE Access, 7, 2957-2968.

Tabachnick, B. G., \& Fidell, L. S. (2001). Using Multivariate Statistics, Fourth Edition. Needham Heights, MA: Allyn \& Bacon.

Thakur, R. (2013). Customer adoption of mobile payment services by professionals across two cities in India: An empirical study using modified technology acceptance model. Business Perspectives and Research, 1(2), 17-30. 
Teo, T. (2010). Examining the influence of subjective norm and facilitating conditions on the intention to use technology among pre-service teachers: a structural equation modelling of an extended technology acceptance model. Asia Pacific Education Review, 11(2), 253-262.

Timones, L. (2019). Total E-wallet Size in Indonesia Likely to Hit \$15 Billion by 2020. [Online] Retrieved from http://www.theasianbanker.com/updates-and-articles/indonesiamobile-payments-still-closely-tied-to-mobile-top-ups-and-online-purchases

Trivedi, J. (2016). Factors determining the acceptance of e-wallets. International Journal of Applied Marketing and Management, 1(2), 42-53.

Uy, G. F. (2019). 5 Digital Marketing Channels That Work Best in Indonesia. Retrieved from https://www.techinasia.com/digital-marketing-channels-indonesia

Venkatesh, V., \& Davis, F. D. (2000). A Theoretical Extension of the Technology Acceptance Model: Four Longitudinal Field Studies. Management Science , 46(2), 186-204.

Venkatesh, V., Thong, J., and Xu, X. (2012). Consumer acceptance and use of information technology: extending the unified theory of acceptance and use of technology. MIS Quarterly, 36(1), 157-178.

Venkatesh, V., Morris, M. G., Davis, G. B., and Davis, F. D. (2003). User acceptance of information technology: toward a unified view. MIS Quarterly, 37(3), 425-478.

Voronenko, D. (2018). Determining Factors of Adoption of Digital Device Wallets by Russian Consumers. (Unpublished Thesis). St. Petersburg University.

Wang, L., \& Yi, Y. (2012). The impact of use context on mobile payment acceptance: An empirical study in China. In Advances in computer science and education (pp. 293299). Springer, Berlin, Heidelberg.

Yan, H., and Yang, Z. (2015). Examining mobile payment user adoption from the perspective of trust. International Journal of u-and e-Service, Science and Technology, 8(1), 117130.

Yang, K., \& Forney, J. C. (2013). The moderating role of consumer technology anxiety in mobile shopping adoption: differential effects of facilitating conditions and social influences. Journal of Electronic Commerce Research, 14(4), 334.

Yeh, M. L., \& Tseng, Y. L. (2017). The College Students' Behaviour Intention of Using Mobile Payments in Taiwan: An Exploratory Research. Singapore, Semantic Scholar Org. 